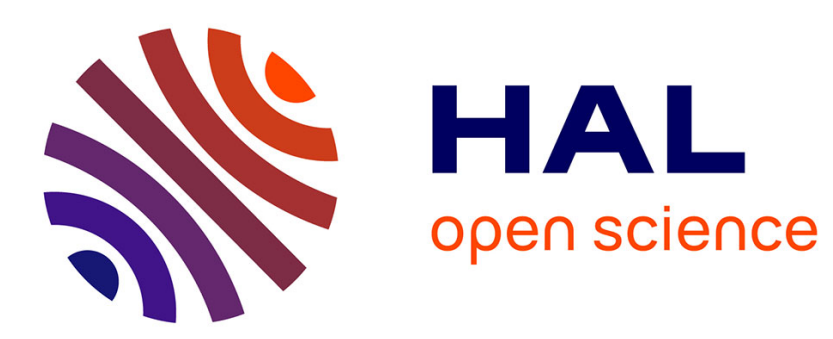

\title{
Thermal fatigue and collapse of waxy suspensions
}

Diogo E V Andrade, Philippe Coussot

\section{To cite this version:}

Diogo E V Andrade, Philippe Coussot. Thermal fatigue and collapse of waxy suspensions. Rheologica Acta, 2020, 59 (5), pp.279-289. 10.1007/s00397-020-01202-y . hal-03249715

\section{HAL Id: hal-03249715 \\ https://hal-enpc.archives-ouvertes.fr/hal-03249715}

Submitted on 4 Jun 2021

HAL is a multi-disciplinary open access archive for the deposit and dissemination of scientific research documents, whether they are published or not. The documents may come from teaching and research institutions in France or abroad, or from public or private research centers.
L'archive ouverte pluridisciplinaire HAL, est destinée au dépôt et à la diffusion de documents scientifiques de niveau recherche, publiés ou non, émanant des établissements d'enseignement et de recherche français ou étrangers, des laboratoires publics ou privés. 


\title{
Thermal fatigue and collapse of waxy suspensions
}

\author{
Diogo E. V. Andrade ${ }^{1,2} \cdot$ Philippe Coussot $^{1}$ \\ Received: 25 November 2019 / Revised: 14 February 2020 / Accepted: 17 February 2020 \\ (C) Springer-Verlag GmbH Germany, part of Springer Nature 2020
}

\begin{abstract}
Due to the existence of a continuous (percolating) network of weak interparticle bonds in a liquid, wax suspensions can behave as "soft breakable (brittle) solids": under the action of either a large stress over a short time or oscillating low stress (fatigue test), the initially solid network of these materials is broken and dispersed in the liquid, which turns them into abruptly ("collapse") and irreversibly to a low viscous fluid. Here we show that the rheological behavior of these materials is not only impacted by the temperature but also by the history of the temperature. The elastic modulus and the yield stress increase when the temperature is decreased, and the data for different concentrations (ranging from 7 to $50 \mathrm{wt} \%$ of wax in oil) and temperatures as a function of the distance to the critical temperature associated with the transition to liquid state, fall along a master curve, which shows some equivalence between temperature and concentration. More surprisingly, the elastic modulus in the linear regime and the yield stress are dependent on the minimum temperature the material has experienced during its preparation. As a consequence of these different characteristics, an original rheological behavior so far essentially observed with very different materials (metals) results, namely thermal fatigue: when the material is submitted to temperature cycling (small temperature amplitude test), the material progressively weakens during each elementary thermal cycle and can finally "collapse" after a sufficient number of cycles, i.e., the elastic modulus in the linear regime decreases from $10^{6}$ to $10^{3} \mathrm{~Pa}$. These findings could have implications in the start-up flow of waxy oils in pipelines since with the help of this technique, the material strength (e.g., the yield stress) and consequently the pressure required to resume the flow can be reduced considerably just by imposing thermal cycles.
\end{abstract}

Keywords Waxy suspensions $\cdot$ Brittle solids $\cdot$ Thermal cracking $\cdot$ Thermal fatigue

\section{Introduction}

The production and transportation of waxy crude oil is a challenge in offshore scenarios. The crude oils, that experience high temperatures in the reservoirs, are submitted to low temperatures during the transportation by pipelines, which are in contact with the seabed at around $4{ }^{\circ} \mathrm{C}$ (Smith and Ramsden 1978; Huang et al. 2011). During the flow in the pipelines, the oil loses heat to the environment and at a given temperaturecalled WAT (wax appearance temperature) - the heaviest

Philippe Coussot

philippe.coussot@ifsttar.fr

1 Laboratoire Navier (ENPC, Univ Gustave Eiffel, CNRS), 77455 Marne-la-Vallée, France

2 Research Center for Rheology and Non-Newtonian Fluids - CERNN, Postgraduate Program in Mechanical and Materials Engineering-PPGEM, Federal University of Technology-Paraná-UTFPR, R. Deputado Heitor Alencar Furtado, 5000 Bloco N-Ecoville, Curitiba, PR 81280-340, Brazil normal hydrocarbon molecules precipitate out in the solution as crystal structures (Paso et al. 2005). At high temperatures, the crude oils behave as Newtonian fluids (Wardhaugh and Boger 1991; Venkatesan et al. 2005), whereas, below the WAT, the solid crystals precipitated in the solution are responsible for three main issues in the production process: (i) the crystals give a non-Newtonian behavior to the material increasing the material viscosity and, as a consequence, the required pumping power to keep the flow also increases (Marchesini et al. 2012); (ii) these solids wax can deposit in the inner surface of the pipelines, in these cases, the PIG (pipeline inspection gauges) must be used to remove the paraffin deposited and the deposition rate must be known in order to determine the wax pigging frequency (Aiyejina et al. 2011); (iii) when the flow is interrupted, the crystals can entrap the oil and yield a solid-like structure to the material, in this case, one must know the strength of the solid structure after the stoppage in order to determine the required pressure to break down the structured material and to resume the flow (Visintin et al. 2005a). 
The knowledge of the rheological behavior of waxy oil is fundamental to design the pumps and the pipelines and to improve the production and transportation process. Although extensive research has been conducted over the past five decades, there are many points regarding the rheological behavior that are not clear in the literature. The majority of the authors agree that these materials present a yield stress at low temperatures, in the sense that after resting for some time, it is necessary a stress larger than a minimum stress to restart the flow. Some authors say that waxy oils are thixotropic materials (Visintin et al. 2005b; de Souza Mendes and Thompson 2012; Teng and Zhang 2013; Dimitriou and McKinley 2014) while others state that waxy oils must be understood as irreversible time-dependent materials since after the shear, the material does not completely recover the viscosity when the applied shear rate is decreased and does not recover the initial solid-like structure at rest (Rønningsen 1992, 2012; Mendes et al. 2015; Andrade and Coussot 2019).

It is well known that waxy oils are thermal and shearhistory dependent (Wardhaugh and Boger 1987). In other words, the different temperatures, cooling rates, and shear applied in the material during the cooling interfere in the crystallization process (nucleation and crystals growth), affecting the morphology of the crystals (Rønningsen et al. 1991; Paso et al. 2005; Yi and Zhang 2011; Andrade et al. 2018) and, as a consequence, influence the macroscopic behavior of the waxy oil at the end of the cooling. The thermal and shear histories are usually evaluated by varying the initial (Smith and Ramsden 1978; Marchesini et al. 2012; Jemmett et al. 2013; Andrade et al. 2015; Dalla et al. 2019) and the final (Davenport and Somper 1971; Hou and Zhang 2010; Mendes et al. 2017) temperature of the cooling, the cooling rate (Lee et al. 2008; Mendes et al. 2017; Andrade et al. 2018), the applied shear during cooling (Venkatesan et al. 2005; Lin et al. 2011; Mendes et al. 2017), and the resting time at the final temperature (Wardhaugh and Boger 1991; Chang et al. 2000; Silva and Coutinho 2004; Mendes et al. 2017). As a general conclusion, it seems that decreasing the final temperature, or increasing the concentration of wax, the material yield stress increases because under these conditions more crystals are formed; the resting time may play a role depending on the composition of the oil, in other words, it seems that for the majority of the crude oils, increasing the resting time at the final temperature increases the strength of the structure (Lin et al. 2011; Van Der Geest et al. 2019); on the other hand, for model waxy oils, the material strength varies in the first minutes of rest and then the elastic modulus and the material yield stress become independent on the resting time (Andrade and Coussot 2019); regarding the dynamic cooling, the final structure of the material is much affected by the shear during the cooling, i.e., the material strength (elastic modulus and yield stress) after dynamic cooling is order of magnitudes lower than the strength of the material obtained after static cooling (Lin et al. 2011; Andrade et al. 2015). Finally, it is interesting to note a non-monotonic variation of the strength of waxy oils in the solid regime as a function of the initial cooling temperature (Marchesini et al. 2012; Andrade et al. 2015; Dalla et al. 2019), the cooling rate (Lee et al. 2008; Andrade et al. 2018), and the shear stress applied during the cooling (Venkatesan et al. 2005).

Here we intend to clarify the impact of thermal changes on waxy crude by focusing on a model system. These materials are commonly used as model materials to study the rheological behavior of waxy crude oil (Singh et al. 2001; Dimitriou et al. 2011; Zhao et al. 2012; Mendes et al. 2015; Andrade et al. 2017) that are transported in subsea pipelines, lubricating mineral oil (Webber 1999, 2001) which can reach low temperatures in some applications, and in a recent study (Andrade and Coussot 2019), it was also proposed that model waxy oils might be used as a model system to simulate and explain natural catastrophic events such as landslides and avalanches.

Although we cannot claim that this material behaves exactly as a typical waxy crude, it can be expected that some fundamental qualitative aspects of the behavior of the model wax suspensions will be found also with waxy crude oils, since both material types are basically made of waxy matter in suspension in a liquid and which crystallize progressively as the temperature is decreased. Moreover, the use of these simple model systems might make it possible to distinguish more easily the original trends of these systems without being too much blurred by various complications due to some additional components.

Model waxy oils are systems composed of paraffin wax mixed in mineral oil. As mentioned previously, these materials behave as a Newtonian fluid at high temperatures, when all the paraffins are dissolved in the oil, and below the WAT, the paraffins precipitate in the oil as wax crystals giving a nonNewtonian behavior to the material. In a previous study (Andrade and Coussot 2019), it was shown that, when cooled at rest (without external stress perturbation in the sample during the cooling), such a material type may be seen as a brittle solid presenting very high elastic modulus (up to $10^{6} \mathrm{~Pa}$ ) and very low critical strain (in the order of $5.10^{-5}$ ) around which the material leaves the linear regime, and finally the material transforms into a simple liquid after some significant shear (Andrade and Coussot 2019). The impact of concentration at a given temperature was analyzed, suggesting that during cooling, the crystals formed are connected by interparticle solid bonds that structure the sample and give the solid-like behavior to the material. Here we intend to analyze how the thermal history impacts these properties.

We first recall in more detail the main characteristics of the material used. Then we further analyze the influence of the temperature in the solid regime of the waxy model oil: we demonstrate that the elastic modulus variations when the temperature decreases at a given concentration are similar to its 
163 variations when the concentration is increased at a given tem164 perature. It is then shown that the waxy oil presents a thermal 165 memory in the sense that the elastic modulus in the linear 166 regime and the yield stress are dependent on the minimum 167 temperature the material has experienced. Finally, a thermal 168 fatigue test (small temperature amplitude tests) may be used to 169 strongly alter the material, as for metals (Starling and Branco 170 1997; Persson et al. 2005) and bitumen (Soenen and 171 Vanelstraete 2003; Kumar-Das et al. 2012), but here this leads 172 to the liquefaction of the material. We start with the experi173 mental section, followed by the results, discussion, and then 174 the main conclusions.

\section{Experimental section}

The model wax oils analyzed are composed of a paraffin wax (Sigma Aldrich 327212 CAS-No:8002-74-2, with a melting point between 58 and $62{ }^{\circ} \mathrm{C}$ ) mixed in a mineral oil (Sigma Aldrich 330779 CAS-No: 8042-47-5) as proposed in previous studies (Dimitriou et al. 2011; Mendes et al. 2015; Andrade et al. 2018; Andrade and Coussot 2019). The samples were stored in an oven at $60^{\circ} \mathrm{C}$, a temperature higher than the solidliquid equilibrium temperature for these materials. It is worth remembering that when mixed in the mineral oil, the wax solubilizes in the liquid and the thermodynamic solid-liquid equilibrium temperature, $T_{\mathrm{eq}, \mathrm{SL}}$, turns a function of the concentration of wax in oil. For example, the $T_{\mathrm{eq}, \mathrm{SL}}$ is $32.0,36.0$, 42.6, for, respectively, 5, 10, and $20 \mathrm{wt} \%$ of wax in oil (Andrade et al. 2017). All the rheometrical tests were performed in the stress-controlled rotational Malvern Kinexus Pro+ rheometer, equipped with serrated $(0.5 \mathrm{~mm}$ groove depth) parallel plates (50 $\mathrm{mm}$ diameter and $1 \mathrm{~mm}$ gap), in which the temperature was controlled by a Peltierthermostatic bath system. Prior to all experiments, the sample was loaded with the aid of a syringe on the rheometer; at this time, the parallel plates and the syringe were also at $60{ }^{\circ} \mathrm{C}$ in order to prevent precipitation of crystals during loading.

As different protocols were used, we are going to describe the experiments before showing each result. But it is important to emphasize that in all the experiments, the rate of change of temperature (cooling or heating rate) was kept at $1.0^{\circ} \mathrm{C} / \mathrm{min}$ and that all the cooling and heating processes were performed statically, i.e., with no shear imposed to the material.

\section{Results}

\section{Material structure in the initial state}

Let us first recall the main characteristics of the waxy oil suspensions in the solid regime, under fixed thermal history. During the cooling, the material reaches the WAT (wax appearance temperature) and the paraffins start to precipitate as crystals structures in the material. It is known that the higher the concentration of wax in oil, the higher the WAT is (Andrade et al. 2017) and as the temperature decreases, more solid paraffins crystallize in the oil. If the cooling is performed quiescently, at a certain point, the crystals can percolate and form a structure in the material. From microscopy image obtained at $25{ }^{\circ} \mathrm{C}$ for $8 \mathrm{wt} \%$ after imposing a cooling rate of $1{ }^{\circ} \mathrm{C} / \mathrm{min}$ from $60{ }^{\circ} \mathrm{C}$ (Fig. 1), the crystals appear to present a needle-like morphology which likely forms a network of inter-particle bonds that is responsible for the initial solidlike behavior of the material. During a stress amplitude oscillatory sweep, the material presents a very high elastic modulus $\left(G^{\prime}\right)$ in the linear regime, in the order of $4.10^{5} \mathrm{~Pa}$ (see Fig. 1), when compared to the typical values for soft-jammed systems (say, a few hundred Pascals, see Coussot et al. (2006)). The material then leaves the linear region (i.e., $G^{\prime}$ starts to decrease with the stress imposed to the sample) at a very low strain amplitude, in the order of $5.10^{-5}$, and the elastic modulus drops by several orders of magnitude. These trends suggested to consider that we are dealing with brittle soft solids.

Still under the same thermal history, it was shown that the elastic modulus in the linear regime starts to increase rapidly beyond a critical concentration of wax up to about $10 \mathrm{wt} \%$. In this range, increasing the concentration just increases the number of needles but does not affect the needle size (see Andrade and Coussot (2019)). The variation of the elastic modulus as a function of the concentration increment above the critical one appeared to be consistent with a percolation phenomenon in a sol-gel transition (De Gennes 1980). Around $10 \mathrm{wt} \%$, the elastic modulus seems to reach a plateau (in the order of $2.10^{6} \mathrm{~Pa}$ ) while the size of the needles rapidly increases, but the structure observed for concentrations beyond $10 \mathrm{wt} \%$ is similar to that observed at smaller concentrations with just a scale change of the elements. Besides the fact that the elastic modulus reaches a plateau, the material yield stress goes on increasing beyond the concentration of $10 \mathrm{wt} \%$. The data presented in Andrade and Coussot (2019) concerning the elastic modulus and the yield stress are summarized in Fig. 2.

Under a given thermal history, the solid to fluid transition for such a material appears to be very abrupt. After preparation, a constant stress is imposed for some time and we follow the resulting deformation in time. At the end of this test, the material is heated again then cooled down, and a new stress value is applied. The material appears to remain in a solid state for sufficiently small stresses, i.e., the deformation remains limited (see Fig. 3). Beyond a critical stress, the material behavior is completely different: the deformation initially slowly increases, then increases suddenly and dramatically, giving the aspect of a vertical jump in a strain vs time diagram: the strain increases up to several orders of magnitude typically in less than one second (see Fig. 3). Thus, when the material reaches a critical 
Fig. 1 Microscopic aspect of the sample (a) and dynamic moduli as a function of the strain amplitude in an oscillatory sweep stress amplitude performed at $1 \mathrm{~Hz}$ (b). Image and test performed at $25^{\circ} \mathrm{C}$ after the static cooling from 60 to $25^{\circ} \mathrm{C}$, with a cooling rate of $1{ }^{\circ} \mathrm{C} / \mathrm{min}$ and a resting time of $10 \mathrm{~min}$. In the image, the bright needles are the wax crystals and the black region is the oil. $8 \mathrm{wt} \%$ of paraffin in oil
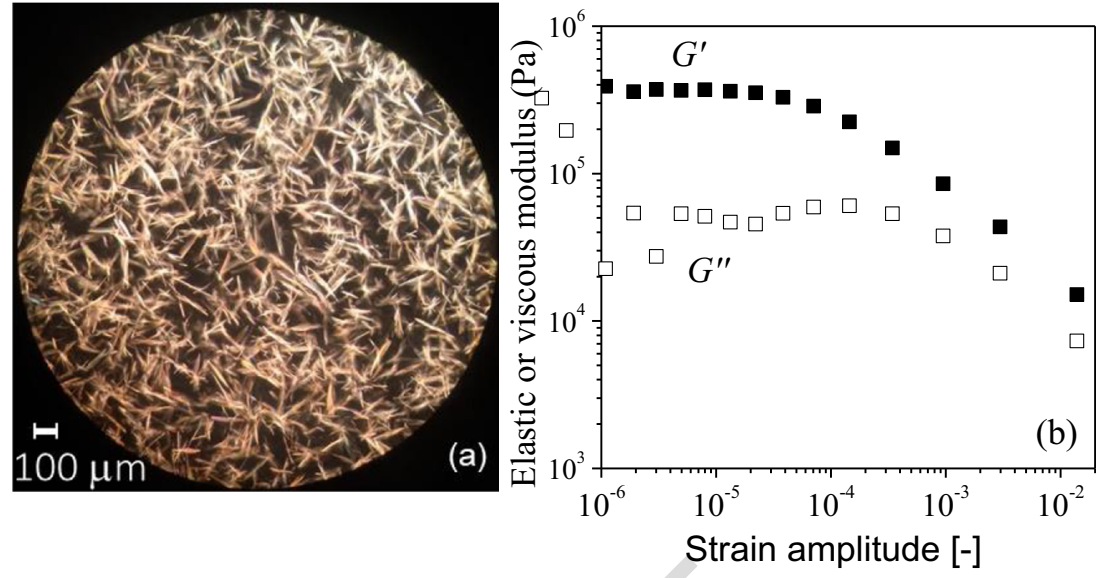

strain $\left(\gamma_{c} \approx 0.1\right)$, the material breaks and presents a "collapse" in the sense that the shear strain evolves orders of magnitude in a very short time. It is interesting to note that a similar behavior was already reported by Wardhaugh and Boger (1991) using crude oils. Then the material reaches a liquid state, with a behavior close to a Newtonian one with a viscosity equal to a few times that of the suspending oil (Andrade and Coussot 2019). Note that this solid-liquid transition appears to be irreversible over a time of observation of several days, since this liquid behavior is observed to persist during such a period. In other words, it seems that after the breakdown of the interparticle bonds, the structure is not recoverable unless the sample is heated to dissolve all the paraffins in the oil and cooled again to the initial solid state. It is also worth noting that a similar collapse may be obtained through a fatigue test, i.e., stress oscillations of amplitude smaller than the yield stress (Andrade and Coussot 2019). Note that a similar trend (irreversible breakage and the fatigue process acting in the material) was observed recently for soft solid (i.e., protein gels) (Saint-Michel et al. 2017).

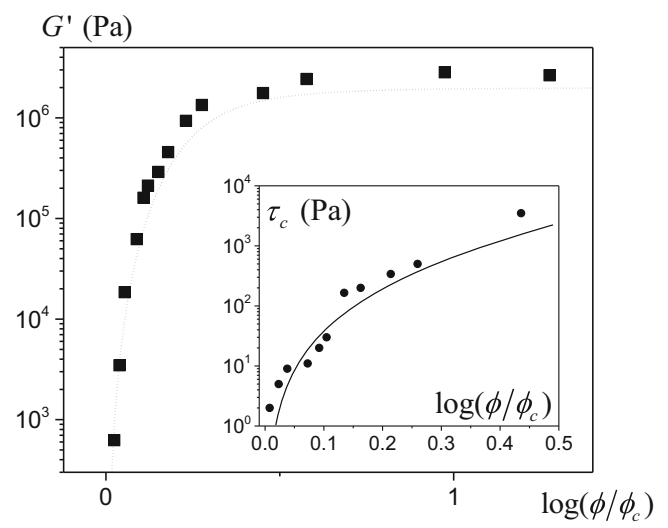

Fig. 2 Elastic modulus (main figure) and yield stress (inset) as a function of the mass concentration of wax in oil $\phi . \phi_{c}$ is the critical concentration (here equal to $5.5 \%$ ) below which the value of the elastic modulus appeared negligible. Data from Andrade and Coussot (2019)
Influence of temperature on the waxy oil rheological behavior

Let us now analyze the influence of temperature on the solid behavior of waxy oils for different wax concentrations. All the samples were cooled with a constant cooling rate of $1{ }^{\circ} \mathrm{C} / \mathrm{min}$ from $60^{\circ} \mathrm{C}$ to the temperature of interest with no perturbation in the sample and then the dynamic moduli were measured. Due to the brittleness of the material, the dynamic moduli were determined by imposing a stress amplitude sweep with a trigger in the rheometer that stops the measurement when the strain amplitude reaches $1.10^{-5}$ in order to avoid some breakdown of the bonds in this measurement. After the oscillatory test, the sample is cooled again to the next temperature with the same cooling rate $\left(1{ }^{\circ} \mathrm{C} / \mathrm{min}\right)$ and rested again during $10 \mathrm{~min}$ before the measurement of the dynamic moduli. This procedure was repeated for all the samples in the range of temperature presented in Fig. 4. It is important to emphasize that in all these measurements, the material is in thermodynamic equilibrium, in other words, if we rest the material for longer time at some given temperature, the dynamic modulus

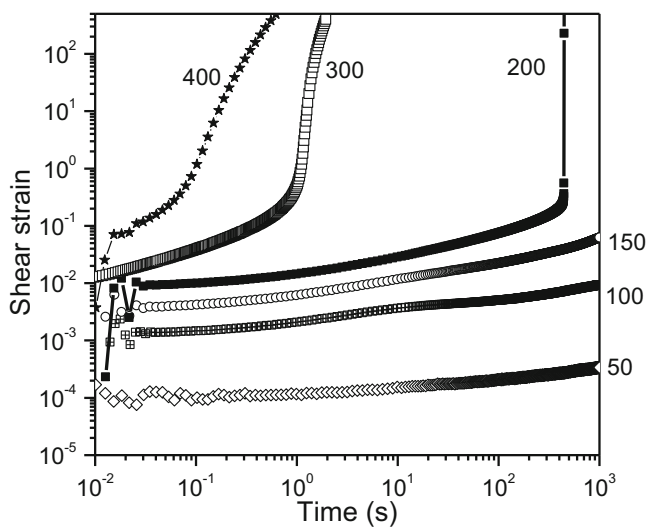

Fig. 3 Creep test performed after the same thermal history that was imposed in the experiments performed in Fig. $1\left(T_{i}=60{ }^{\circ} \mathrm{C}\right.$, cooling rate $1{ }^{\circ} \mathrm{C} / \mathrm{min}$ and $T_{f}=25^{\circ} \mathrm{C}$ ). For each test, the material is heated and cooled again in order to get the same initial state before each experiment. 8 wt $\%$ of paraffin in oil. Data from Andrade and Coussot (2019) 


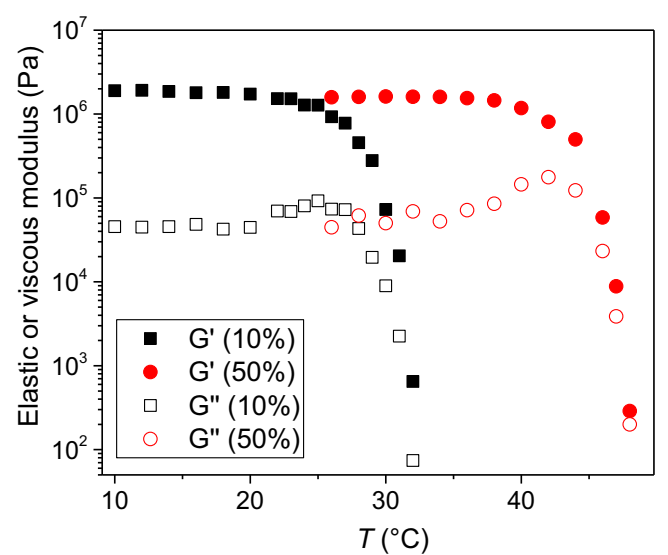

Fig. $4 \mathrm{G}^{\prime}$ and $\mathrm{G}^{\prime \prime}$ as a function of temperature for 10 and $50 \mathrm{wt} \%$ of wax in oil

remains constant (see Fig. 11 in the Appendix). This means that waxy suspensions do not present the aging process as noticed for many yield stress materials (Joshi and Petekidis 2018) in the sense that if the waxy model oil is cooled to a fixed temperature, the elastic modulus evolves up to a fixed value just after the cooling and then does not evolve anymore.

For a given concentration, the elastic modulus starts to increase below some critical temperature $T_{c}$, then it rapidly tends to a plateau at a high level, i.e. $G_{0}^{\prime}$ (see Fig. 4). Remarkably, the shape of $G^{\prime}(T)$ for another (for example smaller) concentration is very similar but simply shifted towards lower temperatures (see Fig. 4). It is also worth emphasizing that the plateau value for the elastic modulus does not depend on the concentration. This means that there is a maximum elastic modulus in the linear regime that cannot be overcome whatever the concentration. This value appears to be close to that for the pure wax (see Andrade and Coussot (2019)). Under these conditions, we can rescale all the data for the different concentrations along a master curve representing $G^{\prime}\left(T_{c}-T\right)$ (see Fig. 5). Figure 5 just shows the results of $G^{\prime}$ obtained using the same protocol as the used in the experiments of Fig. 4, but now for five different concentrations of waxy in oil and changing the axis to $T_{c}-T$. This allows to determine the value of $T_{c}\left[{ }^{\circ} \mathrm{C}\right]$, which increases with the concentration, $\phi[\%]$, (see inset of Fig. 5), and whose variations may be well represented by the following empirical equation:

$T_{c}=8+23.4 \times \log \phi$

On the other hand, remarking that $G^{\prime}-G_{0}^{\prime}$ varies as a powerlaw when $T_{c}-T$ tends to zero, with an exponent around 3, we suggest to represent the rescaled data for the elastic modulus in the following way (see Fig. 5):

$1 / G^{\prime}=\left[1 / G_{0}^{\prime}+0.0002 \times\left(T_{c}-T\right)^{-3}\right]$

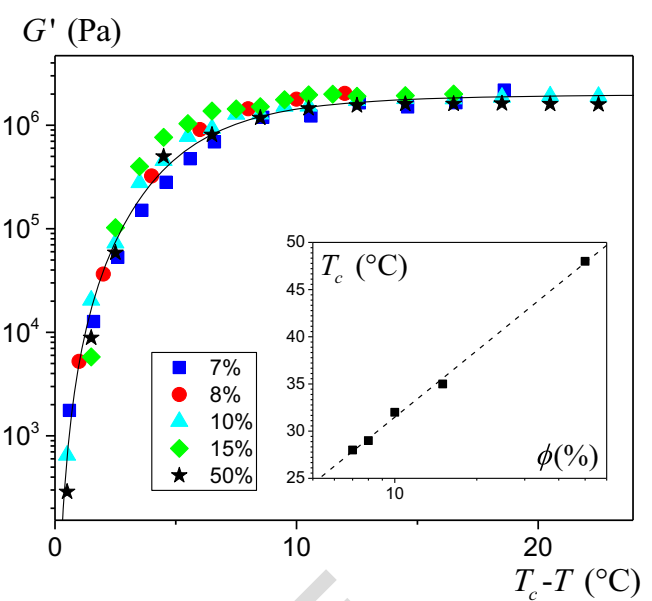

Fig. 5 Elastic modulus for different concentrations as a function of the temperature, and critical temperature $\left(T_{c}\right)$ as a function of concentration (inset). The continuous line is Eq. (2). The dashed line in the inset is Eq. (1)

On the other side, the yield stress for the different temperatures may be determined from a series of creep tests under various stress values, such as those done in Fig. 3, for a material which has been cooled at the desired value. However, this procedure is extremely long, since each yield stress determination requires to impose a large set of stress values, each time preparing again the material in the same state according to the fixed thermal history. In order to obtain more directly a good estimation of the yield stress, we imposed a slowly increasing stress ramp and retained as the yield stress the stress value for which the shear strain exhibits an abrupt increase. This method consisting to impose a slow flow is more direct on some aspects as it provides directly a "yield stress value", whereas the creep tests only provides a range in which lies the yield stress. On the other side, we can fear that considering the particular brittle behavior of these pastes, the result may be somewhat affected by the procedure, but the critical stress obtained from a series of creep tests and from such a slow stress ramp are rather close (see Fig. 12 in the Appendix).

The influence of the temperature on the yield stress for three different concentrations is presented in Fig. 6 in which each experimental point corresponds to a sample that was heated to the initial cooling temperature in order to dissolve all the paraffin in oil and cooled again to the desired temperature. The yield stress also starts to increase from zero below some critical concentration (see inset of Fig. 6), obviously similar to the critical one observed for the elastic modulus. However, here we can observe that the yield stress does not reach a plateau at some temperature; it goes on increasing as the temperature decreases. As a consequence, the data for the yield stress are not simply shifted towards lower temperatures; when the concentration decreases, the yield stress additionally increases (see inset of Fig. 6). It happens that the yield stress 
rescaled by the concentration simply falls along a master curve as a function of the difference between the current and the critical temperatures (see Fig. 6). The data can then well be represented by the following equation (see Fig. 6):

$\tau_{c}=100 \phi\left(T_{c}-T\right)^{2}$

The consistency of this representation of the data can be checked by comparing their prediction of the variation of the elastic modulus and yield stress as a function of the concentration with the data obtained previously (see Fig. 2). Let us now assume that the temperature $T_{0}$ is fixed. In the expressions (2) and (3) the parameter is now $T_{c}$, which varies as a function of $\phi$ according to (1). In addition, we can define a critical concentration $\phi_{c}$ below which the material is not in a solid state at the temperature $T_{0}: \phi_{c}=10^{\left(T_{c}-8\right) / 23.4} T_{0}: \phi_{c}=$ $\exp \left(T_{0}-9\right) / 10.1$. From this equation and the expression (1) we deduce

$T_{c}-T_{0}=23.4 \times \log \phi / \phi_{c}$

which may be inserted in (2) and (3) to obtain the expressions of the elastic modulus and yield stress as a function of the concentration. These expressions appear to rather well correspond to the data obtained at a fixed temperature in a previous study (see Fig. 2). It is important to emphasize that these empirical equations are valid for the model waxy system investigated in this manuscript.

\section{Thermal memory}

It is well known in literature that waxy oils are thermal history dependent in the sense that the final cooling temperature and the cooling rate affect the rheological behavior of the material (see "Introduction"). As far as we know, the effect of a partial

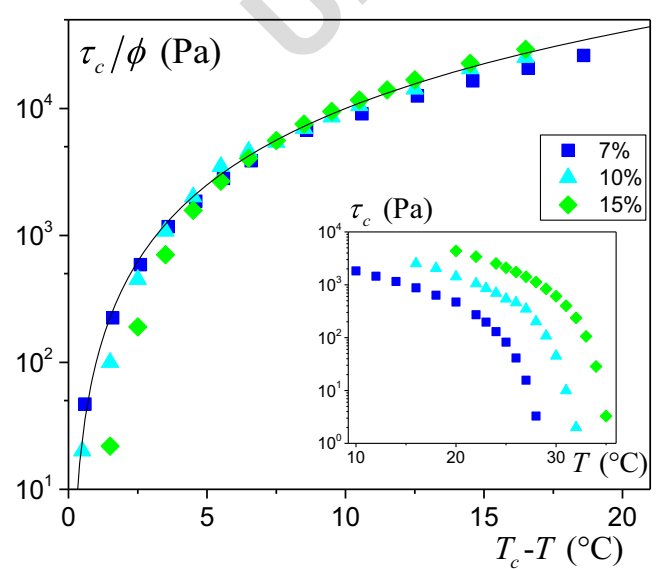

Fig. 6 Impact of temperature on yield stress. The inset shows the yield stress as a function of temperature for different concentrations. The main figure presents the same data with the yield stress rescaled by the concentration and the temperature difference with regard to the critical temperature. The continuous line is Eq. (3) temperature cycle, i.e., temperature decrease then increase, has not been studied. Let us consider a material prepared through a given thermal history (i.e., cooling from 60 to $25^{\circ} \mathrm{C}$ and resting for $10 \mathrm{~min}$ ), and to which we impose a stress level, with now in addition a temperature increase with a constant heating rate of $1{ }^{\circ} \mathrm{C} / \mathrm{min}$. Looking at the strain vs temperature evolution, we see that as in the case of constant temperature for a stress beyond the yield stress (Fig. 3), the material starts to flow abruptly at some critical temperature value during the temperature increase as presented in Fig. 7. The higher the shear stress applied, the lower is the temperature for which this breakdown appears. The main point is that surprisingly, the minimum temperature experienced by the sample (in this case $25^{\circ} \mathrm{C}$ ) affects the yield stress of the material: the magnitude of the stress required to break up the structure and to start-up the flow decreases considerably when the minimum temperature attained is decreased. For example, the material breaks at $100 \mathrm{~Pa}$ when heated from $25{ }^{\circ} \mathrm{C}$ to around $28{ }^{\circ} \mathrm{C}$ while the yield stress of this material when cooled from high temperature to $28^{\circ} \mathrm{C}$ is $201 \mathrm{~Pa}$. In order to facilitate the analysis, the inset table in Fig. 7 compares the yield stress measured after the cooling from high temperature to the desired temperature (values of the Fig. 6 for $10 \mathrm{wt} \%$ measured at isothermal condition) and the values obtained in Fig. 7 in which the sample experienced the minimum temperature of $25{ }^{\circ} \mathrm{C}$ (measured at non-isothermal condition, i.e., during the heating). We can clearly see that the critical stress is much affected by the minimum temperature.

These results suggest an impact of the minimum temperature reached during the thermal history. In order to more directly observe this effect, we now follow the evolution of $\mathrm{G}^{\prime}$ during the cooling down to a given temperature and the

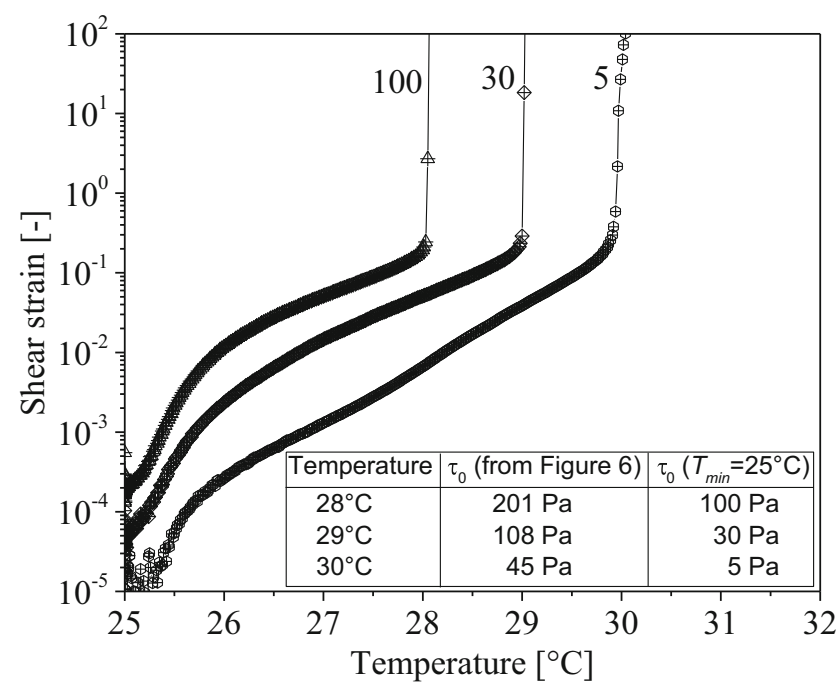

Fig. 7 Analysis of the behavior of the waxy oil during the heating. After cooling, a given stress (indicated in Pascals along the curves in the graph) is applied while the sample is heated at a constant heating rate of $1{ }^{\circ} \mathrm{C} / \mathrm{min}$. The values obtained from Fig. 6 were determined at isothermal conditions. $\phi=10 \mathrm{wt} \%$ 
subsequent heating of the material under our usual heating rate of $1{ }^{\circ} \mathrm{C} / \mathrm{min}$ (Fig. 8a). Note that during this process, the elastic modulus was measured after $10 \mathrm{~min}$ of rest at each temperature of analysis, so that we can expect to have reached a thermal equilibrium at each step of the process. Surprisingly, despite this, the material strength is not only a function of the temperature but also of the thermal history that it has experienced. The $G^{\prime}$ decreases below its initial values associated with the temperature decrease (see Fig. 8a). Moreover, the lower the minimum temperature experienced by the sample, the greater is the lowering of $G^{\prime}$ during the temperature increase (see Fig. 8a). It nevertheless seems that decreasing the minimum temperature to lower than $15{ }^{\circ} \mathrm{C}$ does not affect much more the structure of the material. A similar behavior was observed for other concentrations (see Fig. 13 in the Appendix) and also when the experiment was performed with a serrated surface Couette geometry (results not presented). It is important to emphasize that without this thermal change, i.e., if the sample is kept at the same temperature (e.g., $25^{\circ} \mathrm{C}$ ) and we apply similar oscillation history, we get a constant value of $G^{\prime}$ (see Fig. 11 in the Appendix) and not a decrease in the elastic modulus as presented in Fig. 8.

A similar effect is observed for the yield stress (Fig. 8b). In this case, in these experiments we used the same procedure presented in Fig. 6 but now with a thermal history in which the sample was cooled until a minimum temperature and heated until the temperature of test. It is important to emphasize that for each point, after breakdown, the sample is heated again to $60{ }^{\circ} \mathrm{C}$ in order to dissolve all the wax in oil and the new thermal history was imposed to the material. In other words, the data presented in Fig. $8 \mathrm{~b}$ were not obtained successively for the same sample. We can see that for the two minimum temperatures analyzed ( 25 and $20{ }^{\circ} \mathrm{C}$ ), the thermal history has a great effect on the material yield stress. For example, the yield stress observed at $28{ }^{\circ} \mathrm{C}$ through our standard direct cooling procedure is $201 \mathrm{~Pa}$, but drops to $12 \mathrm{~Pa}$, if the material has been cooled to $20{ }^{\circ} \mathrm{C}$ then heated back to $28^{\circ} \mathrm{C}$.

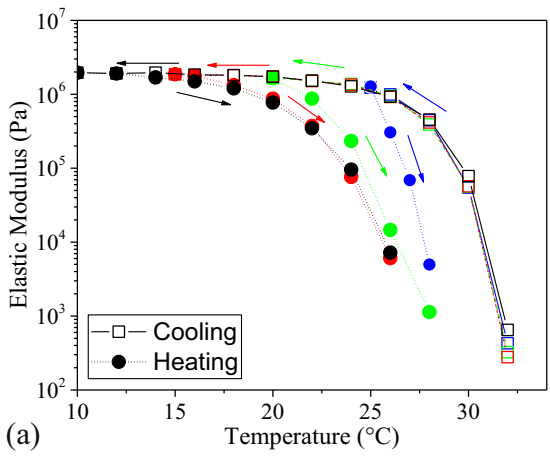

Fig. 8 a Elastic modulus as a function of temperature during the cooling and the heating phases for different minimum temperatures (from right to left) $T_{\min }=25^{\circ} \mathrm{C}$ (blue), $20^{\circ} \mathrm{C}$ (green), $15^{\circ} \mathrm{C}$ (red), and $10^{\circ} \mathrm{C}$ (black)). b
Collapse of the structure by imposing thermal cycle

473

Since the material presents a thermal memory, it seems likely that we can weak the structure by oscillating the temperature. In order to check that, after the standard cooling $\left(60\right.$ to $\left.25^{\circ} \mathrm{C}\right)$, we impose thermal cycles which consist to lower the temperature following a linear ramp, then keeping a constant value, and increasing again the temperature along a short linear ramp to go back to the initial value, then again a plateau, a decrease, and so on (see Fig. 9). It is important to mention that all the thermal history is imposed without any stress perturbation in the sample, and that the dynamic moduli are measured over a relatively short time at the end of each cycle (at a temperature of $25^{\circ} \mathrm{C}$ ) by imposing a stress amplitude sweep with a trigger in the rheometer that stops the measurement when the strain amplitude reaches $10^{-5}$. After each experiment, we could see that even after the thermal cycles, the material is still in the linear regime to strain smaller than $10^{-5}$.

We can see that the dynamic moduli measured at $25^{\circ} \mathrm{C}$ decreases after imposing each cycle in the sample (Fig. 10). This decrease is faster at the beginning then a continuous decrease of $G^{\prime}$ is observed down to values (e.g., after the 20th cycle) which are three orders of magnitude lower than the initial one, and of the order of those observed after the material collapse, i.e., around $2.10^{3} \mathrm{~Pa}$ (as presented in Andrade and Coussot (2019)). In other words, we can "collapse" the structure (decreasing the $G^{\prime}$ from $10^{6}$ to $10^{3} \mathrm{~Pa}$ ) without imposing any stress in the sample, just by thermal cycles. Moreover, the smaller the minimum temperature used in these cycles the stronger the decrease of $G^{\prime}$ along the successive cycles (see Fig. 10), so that the collapse is reached sooner. It is important to emphasize that different protocols were tested (not shown in order to facilitate the understanding of the main message of the paper), and the thermal cycle also affects the mechanical properties of the material at the minimum temperature of the cycle. But in this case, the lower the minimum temperature, the greater is the number of cycles required to weaken the structure of the material.

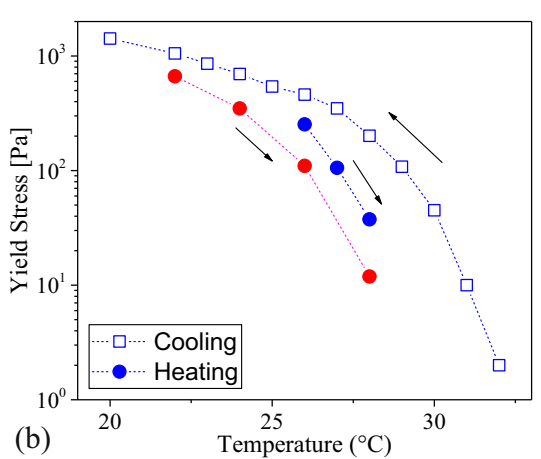

Yield stress (see procedures of determination in the text) as a function temperature for two different minimum temperatures $\left(T_{\min }=25^{\circ} \mathrm{C}\right.$ (blue) and $20{ }^{\circ} \mathrm{C}$ (red)). $\phi=10 \mathrm{wt} \%$ 


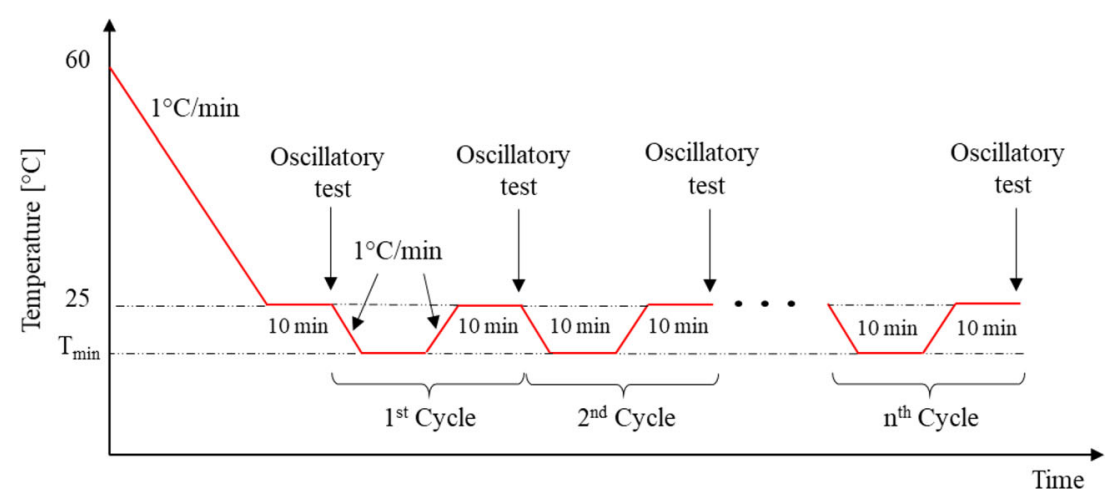

Fig. 9 Scheme of the thermal histories used to analyze the influence of the thermal cycle on the waxy oil. The material was cooled from 60 to $25{ }^{\circ} \mathrm{C}$, then a thermal cycle was imposed between $25{ }^{\circ} \mathrm{C}$ and $T_{\min }$

\section{Discussion}

With our waxy oils we can see a kind of "low temperature cracking" in which the material strength is affected by the minimum temperature experienced by the sample (see Figs. 7 and 8) and also a thermal fatigue process, in which oscillating the temperature the material weakens and suffers a "collapse" without any external stress imposed in the material (Fig. 10). The thermal fatigue cracking is a well-known process in metals (Starling and Branco 1997; Persson et al. 2005) in which the materials fail when exposed to hot work thermal cycles. In these cases, the authors state that the materials are subjected to thermal gradients during the fast temperature changing and, as a consequence, the thermal expansions and contractions are not homogenous throughout the sample, generating different deformation and residual stress in the material. As a consequence, these thermal cycles can lead to fatigue cracking at the surface of the material. It is an important issue for die casting and warm forging industries. On the other hand, the low-temperature cracking and the thermal fatigue cracking at low temperatures have been studied in bitumen to understand failure in asphalt pavements (Soenen and Vanelstraete 2003; Kumar-Das et al. 2012). In these cases, during the cooling, the bitumen is able to shrink and relax the stress up to a certain temperature, but upon further cooling, the bitumen stiffens and is no longer able to relax the stress through a viscous mechanism. These low temperatures generate thermal cracking in the material that is also generated by several thermal cycles.

In order to discuss the physical origin of this thermal fatigue for our waxy oils, we have to refer to their specific structure in the solid regime (as compared to metals): this is a rather "open" structure built on a percolated network of needles linked by solid bonds. Moreover, the macroscopic behavior relies on the links between the needles, as only the links are broken during the solid-liquid transition, i.e., the needles remain intact (see Andrade and Coussot (2019)). (minimum temperature). In all the temperature ramps, the rate of change of temperature is $1{ }^{\circ} \mathrm{C} / \mathrm{min}$ regardless of whether cooling or heating is applied
This implies that what occurs inside the needles as a result of temperature variations should play a negligible role; they can be considered as rigid, and formed during the first thermal cycle after preparation. Under these conditions, the impact of temperature on the elastic modulus and yield stress is associated with the exact state of crystallization of the material composing the links between needles. If the structure could simply be considered as formed of the association of a number of crystals increasing when the temperature decreases, decreasing values of the yield stress, and the elastic modulus would be obtained for increasing temperatures. This is indeed what we observe. If in addition each crystal formation or fusion is obtained at the same given temperature, for low temperature variations, the thermal history cannot have any impact: the current temperature solely imposes the structure state, hence the mechanical strength of the material. If the temperature of crystallization is lower than the temperature of fusion, there might be some hysteresis, but this will only play a role during the first thermal cycle, with little to no long-term evolution.

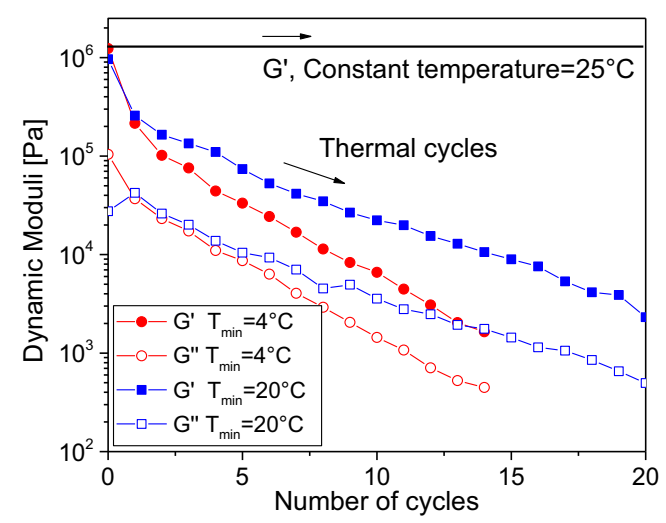

Fig. 10 Dynamic moduli measured at $25{ }^{\circ} \mathrm{C}$ after thermal cycles (see procedure in Fig. 9). The first point (Number of cycles $=0$ ) corresponds to the end of the cooling at rest from 60 to $25^{\circ} \mathrm{C}$ and the other points correspond to the subsequent measurements after an increasing number of cycles. The upper continuous line represents the value of $G^{\prime}$ at a constant temperature, i.e., without thermal cycle. $\phi=10 \mathrm{wt} \%$ 
This implies that, in order to explain the thermal fatigue of these materials, we necessarily have to consider that some steps of the process alter the material more than strictly in relation with crystallization and fusion of some elements of the structure of the material composing the links between the needles. In a way similar to the thermal fatigue in metals, we can suggest that the partial fusion of some crystals during the step of temperature increase, alters the structure of the material at other locations than the strict crystal under consideration. This could be due to a slighter density increase obtained after crystallization, tending to compact the structure, while the fusion of some crystals under a slight temperature increase would lead to a slight density decrease tending to break some "contacts" (or more globally speaking, propagate fracture) between crystals otherwise not altered by the thermal cycle. The succession of such cycles would then break more and more such contacts.

\section{Conclusions}

The main conclusions of the work can be summarized as follows:

- The waxy oil is a brittle material whose mechanical properties are affected by the minimum temperature experienced by the material; for example, the elastic modulus analyzed at $28^{\circ} \mathrm{C}$ can decrease three orders of magnitude and the yield stress can decrease two orders of magnitude just by cooling statically the material to $20^{\circ} \mathrm{C}$ and heating again to $28^{\circ} \mathrm{C}$.

- Lower minimum temperatures imply a more pronounced impact of the thermal cycle;

- If the material is thermally cycled, we can observe thermal fatigue in the material. In other words, without imposing any stress in the material, just by successive thermal cycles, the structure "collapses" and the material liquefies.

- This behavior could lead to important implications in the start-up flow of waxy oils, since we show that it is possible to decrease considerably the material yield stress just by cycling the temperature of the material.

Understanding the exact physical origin of this behavior would require to develop imaging technique at a very low scale inside the wax link between needles.

Acknowledgments D.E.V.A acknowledges CAPES (Coordination for the Improvement of Higher Education Personnel - Brazil) (Process: 88881.170234/2018-01) for the Postdoctoral Fellowship.

\section{Appendix}

Dynamic moduli as a function of time

After the static cooling from 60 to $25{ }^{\circ} \mathrm{C}$ with $1{ }^{\circ} \mathrm{C} / \mathrm{min}$ of cooling rate, the material was kept at rest during $10 \mathrm{~min}$ and then a constant stress amplitude oscillatory test was applied in the material in the linear regime (stress amplitude $=10 \mathrm{~Pa}$ and frequency $=1 \mathrm{~Hz}$ ) and the dynamic moduli were analyzed over time (Fig. 11). It is possible to see that in the linear regime - and if the temperature is not changed - the strength of the material (e.g., the elastic modulus) remains constant over time.

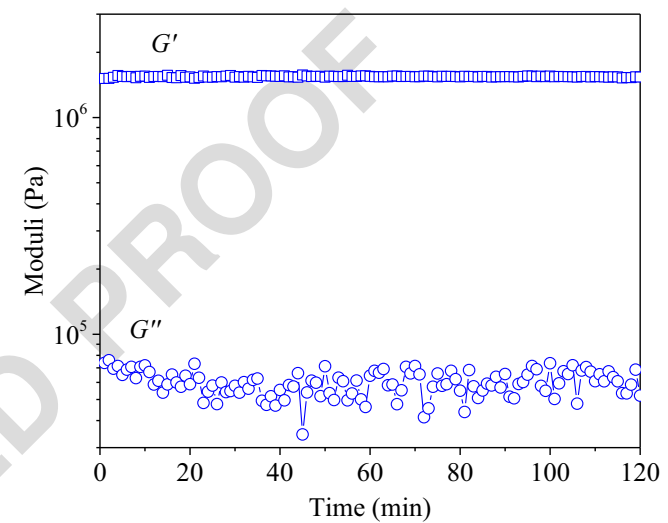

Fig. $11 G^{\prime}$ and $G^{\prime \prime}$ as a function of time measured at a constant temperature of $25^{\circ} \mathrm{C}$ after a static cooling with $T_{i}=60{ }^{\circ} \mathrm{C}$ and cooling rate of $1{ }^{\circ} \mathrm{C} / \mathrm{min} . \phi=10 \mathrm{wt} \%$

\section{Yield stress: creep test $\times$ stress ramp}

As discussed in the text, the yield stress may be determined from a series of creep tests under various stress values, as presented for $8 \mathrm{wt} \%$ (Fig. 3). However, with this procedure, a precise value of the yield stress can be obtained only after a great number of tests. As in this work, we are analyzing the influence of the concentration and different thermal histories on the yield stress; determining the yield stress with a series of creep tests would be a very slow process and almost prohibitive due to the time need to get the yield stress for each condition. In order to obtain more directly a good estimation of the yield stress, we imposed a slowly increasing stress ramp and retained as the yield stress, the stress value for which the shear strain exhibits an abrupt increase. Just to compare, we are showing again the results of creep test (Fig. 12a) presented previously (Andrade and Coussot 2019) for $10 \mathrm{wt} \%$ of wax in oil. In these tests, we can see that the material breaks if a stress of $500 \mathrm{~Pa}$ or higher is applied in the sample. If the same thermal history is applied in the sample but instead of a plateau of stress, we impose a stress ramp, one can see at which stress the material breaks analyzing the shear strain as a function of stress (Fig. 12b). We can see that for the stress ramp, the material was broken when the stress reached around $550 \mathrm{~Pa}$.
613

614

615

616

617

618

619

620 


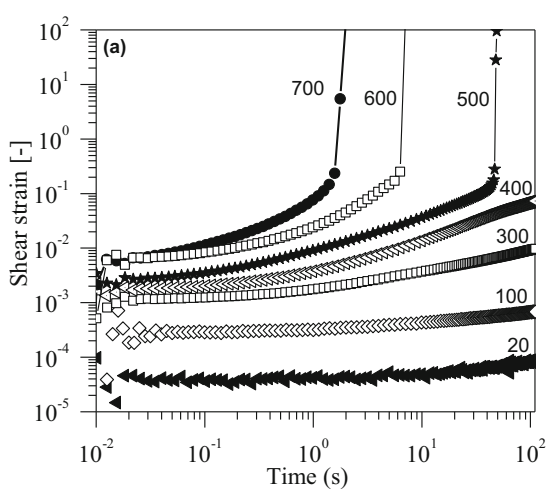

Fig. 12 Experiments performed with $10 \mathrm{wt} \%$ of wax in oil, $T_{i}=60{ }^{\circ} \mathrm{C}$, $1{ }^{\circ} \mathrm{C} / \mathrm{min}$ of cooling rate, $T_{f}=25^{\circ} \mathrm{C}$, and $10 \mathrm{~min}$ of resting time. a Shear strain as a function of time in the creep test. Before each plateau of stress, the sample is heated and cooled again using the same thermal history.

\section{Thermal memory for different concentrations}

The same experiment presented for $10 \mathrm{wt} \%$ (see Fig. 8a) was performed for two other concentrations, $7 \mathrm{wt} \%$ (see Fig. 13a)
Fig. $13 \mathrm{G}^{\prime}$ as a function of (squares in blue) and for the same sample during the heating (stars in red) for $\mathbf{a} \phi=7 \mathrm{wt} \%$ and $\mathbf{b} \phi=$ 8 wt\% temperature during the cooling

\section{References}

Aiyejina A, Chakrabarti DP, Pilgrim A, Sastry MKS (2011) Wax formation in oil pipelines: a critical review. Int J Multiphase Flow 37:671694. https://doi.org/10.1016/j.ijmultiphaseflow.2011.02.007

Andrade DEV, Coussot P (2019) Brittle solid collapse to simple liquid for a waxy suspension. Soft Matter 15:8766-8777. https://doi.org/10. 1039/c9sm01517e

Andrade DEV, da Cruz ACB, Franco AT, Negrão COR (2015) Influence of the initial cooling temperature on the gelation and yield stress of waxy crude oils. Rheol Acta 54:149-157. https://doi.org/10.1007/ s00397-014-0812-0

Andrade DEV, Marcelino Neto MA, Negrão COR (2018) Nonmonotonic response of waxy oil gel strength to cooling rate. Rheol Acta 57:673-680. https://doi.org/10.1007/s00397-018-1108-6

Andrade DEV, Marcelino Neto MA, Negrão COR (2017) The importance of supersaturation on determining the solid-liquid equilibrium temperature of waxy oils. Fuel 206:516-523. https://doi.org/10.1016/j. fuel.2017.06.042

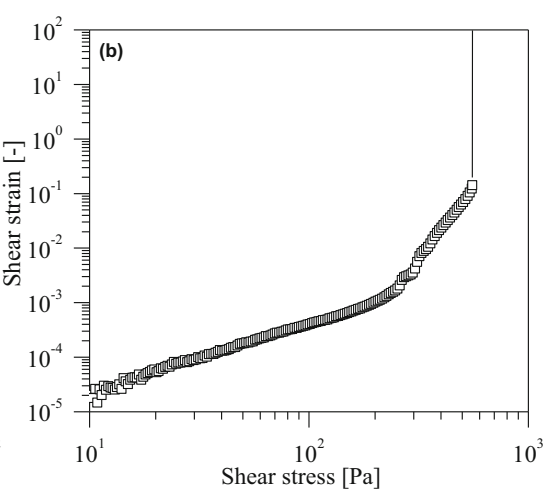

(Results presented in data presented in Andrade and Coussot (2019)). b Shear strain as a function of shear stress in the stress ramp stress. In this measurement, the stress was increased logarithmically at a rate of one order of magnitude per each $10 \mathrm{~min}$

and $8 \mathrm{wt} \%$ (see Fig. 13b). We can see that the minimum temperature also affects the strength of the material for other concentrations.
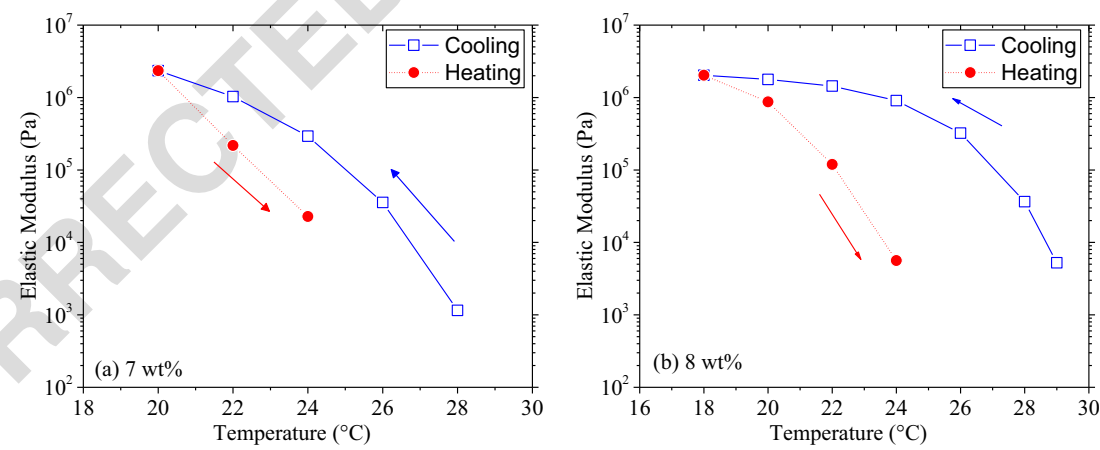

Chang C, Boger DV, Nguyen QD (2000) Influence of thermal history on the waxy structure of statically cooled waxy crude oil. SPE J 5:2-3. https://doi.org/10.2118/57959-PA

Coussot P, Tabuteau H, Chateau X et al (2006) Aging and solid or liquid behavior in pastes. J Rheol (N Y N Y) 50:975-994. https://doi.org/ $10.1122 / 1.2337259$

Dalla LFR, Soares EJ, Siqueira RN (2019) Start-up of waxy crude oils in pipelines. J Nonnewton Fluid Mech 263:61-68. https://doi.org/10. 1016/j.jnnfm.2018.11.008

Davenport TC, Somper RSH (1971) The yield value and breakdown of crude oil gels. J Inst Pet 57:86-105

De Gennes P (1980) Percolation : quelques systemes nouveaux. J Phys Colloq 41:17-26

de Souza Mendes PR, Thompson RL (2012) A critical overview of elasto-viscoplastic thixotropic modeling. J Nonnewton Fluid Mech 187-188:8-15. https://doi.org/10.1016/j.jnnfm.2012.08.006

Dimitriou CJ, McKinley GH (2014) A comprehensive constitutive law for waxy crude oil: a thixotropic yield stress fluid. Soft Matter 10: 6619-6644. https://doi.org/10.1039/c4sm00578c 
689

690

691

692

693

694

695

696

697

698

699
Silva JAL, Coutinho JAP (2004) Dynamic rheological analysis of the gelation behaviour of waxy crude oils. Rheol Acta 43:433-441. https://doi.org/10.1007/s00397-004-0367-6 the yielding and flow of model waxy crude oils. Energy Fuel 25: 3040-3052. https://doi.org/10.1021/ef2002348

Hou L, Zhang J (2010) A study on creep behavior of gelled Daqing crude oil. Pet Sci Technol 28:690-699. https://doi.org/10.1080/ 10916460902804648

Huang Z, Lu Y, Hoffmann R et al (2011) The effect of operating temperatures on wax deposition. Energy Fuel 25:5180-5188. https://doi. org/10.1021/ef201048w

Jemmett MR, Magda JJ, Deo MD (2013) Heterogeneous organic gels: rheology and restart. Energy Fuel 27:1762-1771. https://doi.org/10. 1021/ef3014629

Joshi YM, Petekidis G (2018) Yield stress fluids and ageing. Rheol Acta 57:521-549. https://doi.org/10.1007/s00397-018-1096-6

Kumar-Das P, Jelagin D, Birgisson B, Kringos N (2012) Micromechanical investigation of low temperature fatigue cracking behaviour of bitumen. In: 7th RILEM international conference on cracking in pavements. pp 1281-1290

Lee HS, Singh P, Thomason WH, Fogler HS (2008) Waxy oil gel breaking mechanisms: adhesive versus cohesive failure. Energy Fuel 22: 480-487. https://doi.org/10.1021/ef700212v

Lin M, Li C, Yang F, Ma Y (2011) Isothermal structure development of Qinghai waxy crude oil after static and dynamic cooling. J Pet Sci Eng 77:351-358. https://doi.org/10.1016/j.petrol.2011.04.010

Marchesini FH, Alicke AA, de Souza Mendes PR, Ziglio CM (2012) Rheological characterization of waxy crude oils: sample preparation. Energy Fuel 26:2566-2577. https://doi.org/10.1021/ef201335c

Mendes R, Vinay G, Coussot P (2017) Yield stress and minimum pressure for simulating the flow restart of a waxy crude oil pipeline. Energy Fuel 31:395-407. https://doi.org/10.1021/acs.energyfuels. $6 \mathrm{~b} 02576$

Mendes R, Vinay G, Ovarlez G, Coussot P (2015) Reversible and irreversible destructuring flow in waxy oils: an MRI study. J NonNewtonian Fluid Mech 220:77-86. https://doi.org/10.1016/j. jnnfm.2014.09.011

Paso K, Senra M, Yi Y et al (2005) Paraffin polydispersity facilitates mechanical gelation. Ind Eng Chem Res 44:7242-7254. https:// doi.org/10.1021/ie050325u

Persson A, Hogmark S, Bergström J (2005) Thermal fatigue cracking of surface engineered hot work tool steels. Surf Coat Technol 191:216 227. https://doi.org/10.1016/j.surfcoat.2004.04.053

Rønningsen HP (1992) Rheological behaviour of gelled, waxy North Sea crude oils. J Pet Sci Eng 7:177-213. https://doi.org/10.1016/09204105(92)90019-W

Rønningsen HP (2012) Rheology of petroleum fluids. Annu Trans Nord Rheol Soc 20:11-18

Rønningsen HP, Bjorndal B, Hansen AB, Pedersen WB (1991) Wax precipitation from North Sea crude oils. 1. Crystallization and dissolution temperatures, and Newtonian and non-Newtonian flow properties. Energy Fuel 5:895-908. https://doi.org/10.1021/ ef00030a019

Saint-Michel B, Gibaud T, Manneville S (2017) Predicting and assessing rupture in protein gels under oscillatory shear. Soft Matter 13:26432653. https://doi.org/10.1039/C7SM00064B
Singh P, Venkatesan R, Fogler HS, Nagarajan NR (2001) Morphological evolution of thick wax deposits during aging. AICHE J 47:6-18. https://doi.org/10.1002/aic.690470103

Smith PB, Ramsden RMJ (1978) The prediction of oil gelation in submarine pipelines and the pressure requered for restarting flow. In: Europeans Offshore Petroleum Conference \& Exhibition

Soenen H, Vanelstraete A (2003) Performance indicators for low temperature cracking. In: Sixth International RILEM Symposium on Performance Testing and Evaluation of Bituminous Materials. pp $458-464$

Starling CMD, Branco JRT (1997) Thermal fatigue of hot work tool steel with hard coatings. Thin Solid Films 308-309:436-442. https://doi. org/10.1016/S0040-6090(97)00600-7

Teng H, Zhang J (2013) A new thixotropic model for waxy crude. Rheol Acta 52:903-911. https://doi.org/10.1007/s00397-013-0729-z

Van Der Geest C, Guersoni VCB, Bannwart AC (2019) Experimental study of the time to restart the flow of a gelled waxy crude in rheometer and pipeline. J Pet Sci Eng 181:106247. https://doi.org/ 10.1016/j.petrol.2019.106247

Venkatesan R, Nagarajan NR, Paso K et al (2005) The strength of paraffin gels formed under static and flow conditions. Chem Eng Sci 60: 3587-3598. https://doi.org/10.1016/j.ces.2005.02.045

Visintin RFG, Lapasin R, Vignati E et al (2005a) Rheological behavior and structural interpretation of waxy crude oil gels. Langmuir 21: 6240-6249. https://doi.org/10.1021/la050705k

Visintin RFG, Lapasin R, Vignati E, D'Antona P, Lockhart TP (2005b) Rheological behavior and structural interpretation of waxy crude oil gels. Langmuir 21:6240-6249. https://doi.org/10.1021/la050705k

Wardhaugh LT, Boger DV (1987) Measurement of the unique flow properties of waxy crude oils. Chem Eng Res Des 65:74-83

Wardhaugh LT, Boger DV (1991) The measurement and description of the yielding behavior of waxy crude oil. J Rheol 35:1121-1156. https://doi.org/10.1122/1.550168

Webber RM (1999) Low temperature rheology of lubricating mineral oils: effects of cooling rate and wax crystallization on flow properties of base oils. J Rheol 43:911-931. https://doi.org/10.1122/1. 551045

Webber RM (2001) Yield properties of wax crystal structures formed in lubricant mineral oils. Ind Eng Chem Res 40:195-203. https://doi. org/10.1021/ie000417d

Yi S, Zhang J (2011) Relationship between waxy crude oil composition and change in the morphology and structure of wax crystals induced by pour-point-depressant beneficiation. Energy Fuel 25:1686-1696. https://doi.org/10.1021/ef200059p

Zhao Y, Kumar L, Paso K, Ali H, Safieva J, Sjöblom J (2012) Gelation and breakage behavior of model wax - oil systems: rheological properties and model development. Ind Eng Chem Res 51:81238133

Publisher's note Springer Nature remains neutral with regard to jurisdictional claims in published maps and institutional affiliations. 